\title{
PEMANFAATAN LIMBAH BATU GRANIT SEBAGAI CAMPURAN AGREGAT PADA AC-L
}

\author{
${ }^{1}$ Ahmad Ridwan, ${ }^{2}$ Yosef Cahyo Setianto Poernomo \\ ${ }^{1 \& 2}$ Staf Pengajar Program Studi Teknik Sipil Fakultas Teknik Universitas Kadiri
}

\begin{abstract}
Granite waste is generated at the time of processing the granite rock that is not utilized, it can be also a rest - the rest of the project. Utilization of waste material roughness to granite road is one way to reduce the waste of the granite. This research aims to know the benefits of waste granite coarse aggregate as substitute against marshall on the mix characteristic laston or ACb. ingredients used include: Semen Gresik brand Filler, sand purchased from stores building in Kediri, Grey stone which in may from Winongsari Grogol, corals that are purchased from shops in Kediri, Asphalt comes from Pertamina, granite Waste obtained from the project. Mix laston or AC-L with granite rock waste as a substitute for coarse aggregate using a variation of $10 \%, 20 \%$, and $30 \%$. The results of this research it is known that the use of granite waste can enhance the characteristics of Marshall. Mix the waste with best laston granite aggregate as substitute coarse waste levels obtained at 20\%, with the following results: Marshall Stability $1050.67 \mathrm{~kg}$, Melting/4.00 mm Flow, Marshall Quotient $262.67 \mathrm{~mm}$.
\end{abstract}

Keywords: mixed laston, waste characteristics, granite marshall test

\section{PENDAHULUAN}

Perkerasan lentur merupakan perkerasan yang paling diminati pada struktur perkerasan jalan raya. Daya dukung yang besar sehingga mampu menerima beban lalu lintas kendaraan ditambah biaya konstruksi yang lebih ekonomis merupakan kelebihan dari perkerasan lentur dibandingkan dengan perkerasan lainnya. Di Indonesia saat ini banyak sekali limbah batu granit dari sisa sisa konstruksi. Batu granit adalah salah satu batu yang kuat, maka kepadatan batu granit tergolong besar. Karena itu agar tidak terbuang percuma, saya mencoba membuat penelitian tentang pemanfaatan limbah batu granit pada campuran laston untuk gradasi agregat.

Identifiakasi masalah pada tugas akhir ini karena Adanya banyak limbah granit yang dapat dimanfaatkan sebagai campuran agregat pada perkerasan jalan

\section{METODE PENELITIAN}

2.1 Tahapan Penelitian

2.1.1 Pengumpulan Material

1. Persiapan Benda Uji
Pengeringan agregat, sampai beratnya tetap pada suhu $105^{\circ} \mathrm{C}$.

2. Penentuan Suhu Pencampuran dan Pemadatan

Suhu pencampuran dan pemadatan harus ditentukan sehingga bahan pengikat yang dipakai menghasilkan viscositas.

\subsubsection{Persiapan JMF ( Job Mix Formula)}

Dalam penelitian kali ini mengunakan JMF ( Job Mix Formula) yang sudah ada.

Tabel 1 Proporsi campuran agregat pada Laston / AC-(L)

\begin{tabular}{|c|c|c|c|c|}
\hline No & Bahan & Jumlah \% & Individual & Comulative \\
\hline 1 & Agragat Kasar & 25 & 300 gram & 300 gram \\
\hline 2 & Agragat Medium & $33 \%$ & 396 gram & 696 gram \\
\hline 3 & Agragat Halus & $40 \%$ & 480 gram & 1176 gram \\
\hline 4 & Filler & $2 \%$ & 24 gram & 1200 gram \\
\hline
\end{tabular}


Tabel 2 Penyesuaian proporsi campuran Laston / AC-(L)

Sumber : (Data (JMF) Job Mix Formula Acuan)

\begin{tabular}{|c|c|c|c|c|}
\hline No & Bahan & Jumlah \% & Individual & Comulative \\
\hline 1 & Agras & $23.43 \%$ & 281 gram & 281.2 gram \\
\hline 2 & Agragat Medium & $30.92 \%$ & 371 gram & 652.2 gram \\
\hline 3 & Agragat Halus & $37.48 \%$ & 450 gram & 1102 gram \\
\hline 4 & Filler & $1.87 \%$ & 22 gram & 1124 gram \\
\hline 5 & Aspal & $6.3 \%$ & 76 gram & 1200 gram \\
\hline
\end{tabular}

\subsubsection{Pembuatan Sampel}

- Panaskan agregat dalam panic kira-kira $180^{\circ} \mathrm{C}\left( \pm 20^{\circ} \mathrm{C}\right.$ diatas suhu pencampuran $)$

- Panaskan aspal beserta tempat aspal $15^{\circ} \mathrm{C}$ dibawah suhu pemanasan agregat. Tuangkan aspal sebanyak yang dibutuhkan ke dalam agregat yang sudah dipanaskan tersebut di atas perimbangan. Kemudian aduklah dengan cepat pada suhu sesuai pencampuran sampai agregat terlapis aspal secara merata (homogen).

\section{Pemadatan Benda Uji}

Bersihkan perlengkapan mold serta bagian muka penumbuk dengan seksama dan panaskan sampai suhu antara 93,3 dan $148,90^{\circ} \mathrm{C}$. Letakkan selembar kertas saring penghisap yang sudah digunting menurut ukuran diameter mold ke dalam dasar mold, kemudian masukkanlah seluruh campuran ke dalam mold lalu tusuk-tusuk campuran keraskeras dengan spatula yang dipanaskan 15 kali keliling pinggirannya dan 10 kali di bagian dalamnya. Lepaskan lehernya dan ratakan permukaan campuran dengan mengggunakan sendok semen menjadi bentuk yang sedikit cembung. Waktu akan dipadatkan suhu campuran harus dalam batas-batas suhu pemadatan seperti disebutkan pada keterangan di atas.

\subsubsection{Perancangan Campuran / Mix Design}

Setelah pengujian seluruh material penyusun yang diperlukan maka langkah berikutnya yaitu merancang campuran agar diperoleh komposisi campuran sesuai dengan target yang diharapkan.
Tabel 3 Proporsi campuran agregat pada Laston / AC-(L) dengan variasi limbah batu granit $10 \%$

\begin{tabular}{|c|c|c|c|cc|cc|}
\hline $\mathbf{N}_{0}$ & \multicolumn{2}{|c|}{ Bahan } & \multicolumn{2}{|c|}{ Jumlah \% } & \multicolumn{2}{|c|}{ Individual } & \multicolumn{2}{|c|}{ Comulative } \\
\hline 1 & AgragatKasar & 22.5 & $\%$ & 270 & gram & 270 & gram \\
\hline 2 & Agragat Medium & 33 & $\%$ & 396 & gram & 666 & gram \\
\hline 3 & Agragat Halus & 40 & $\%$ & 480 & gram & 1146 & gram \\
\hline 4 & Filler & 2 & $\%$ & 24 & gram & 1170 & gram \\
\hline 5 & Limbah Granit & 2.5 & $\%$ & 30 & gram & 1200 & gram \\
\hline
\end{tabular}

Sumber : (Data diolah)

Tabel 4 Penyesuaian proporsi campuran Laston / AC-(L) dengan variasi limbah batu granit $10 \%$

\begin{tabular}{|c|c|c|c|cc|cc|}
\hline$N_{0}$ & Bahan & \multicolumn{2}{|c|}{ Jumlah \% } & \multicolumn{2}{|c|}{ Individual } & \multicolumn{2}{|c|}{ Comulative } \\
\hline 1 & Agragat Kasar & 21.09 & $\%$ & 253 & gram & 253 & gram \\
\hline 2 & Agragat Medium & 30.92 & $\%$ & 371 & gram & 624.1 & gram \\
\hline 3 & Agragat Halus & 37.48 & $\%$ & 449.8 & gram & 1074 & gram \\
\hline 4 & Filler & 1.87 & $\%$ & 22.44 & gram & 1096 & gram \\
\hline 5 & Aspal & 6.3 & $\%$ & 75.6 & gram & 1172 & gram \\
\hline 6 & Limbah Granit & 2.343 & $\%$ & 28.12 & gram & 1200 & gram \\
\hline
\end{tabular}

Sumber : (Data diolah)

Tabel 5 Proporsi campuran agregat pada Laston / AC-(L) dengan variasi limbah batu granit $20 \%$

\begin{tabular}{|c|c|cc|ccc|cc|}
\hline N0 & Bahan & \multicolumn{2}{|c|}{ Jumlah \% } & \multicolumn{2}{|c|}{ Individual } & \multicolumn{2}{c|}{ Comulative } \\
\hline 1 & Agragat Kasar & 20 & $\%$ & 240 & gram & 240 & gram \\
\hline 2 & Agragat Medium & 33 & $\%$ & 396 & gram & 636 & gram \\
\hline 3 & Agragat Hallus & 40 & $\%$ & 480 & gram & 1116 & gram \\
\hline 4 & Filler & 2 & $\%$ & 24 & gram & 1140 & gram \\
\hline 5 & Limbah Granit & 5 & $\%$ & 60 & gram & 1200 & gram \\
\hline
\end{tabular}

Sumber : (Data diolah) 
Tabel 6 Penyesuaian proporsi campuran Laston / AC-(L) dengan variasi limbah batu granit $20 \%$

\begin{tabular}{|c|c|cc|cc|cc|}
\hline No & Bahan & \multicolumn{2}{|c|}{ Jumlah \% } & \multicolumn{2}{|c|}{ Individual } & \multicolumn{2}{c|}{ Comulative } \\
\hline 1 & Agragat Kasar & 18.74 & $\%$ & 224.9 & gram & 224.9 & gram \\
\hline 2 & Agragat Medium & 30.92 & $\%$ & 371 & gram & 596 & gram \\
\hline 3 & Agragat Halus & 37.48 & $\%$ & 449.8 & gram & 1046 & gram \\
\hline 4 & Filler & 1.87 & $\%$ & 22.44 & gram & 1068 & gram \\
\hline 5 & Aspal & 6.3 & $\%$ & 75.6 & gram & 1144 & gram \\
\hline 6 & Limbah Granit & 4.69 & $\%$ & 56.23 & gram & 1200 & gram \\
\hline
\end{tabular}

Sumber : (Data diolah)

Tabel 7 Proporsi campuran agregat pada Laston / AC-(L) dengan variasi limbah batu granit 30\%

\begin{tabular}{|c|c|c|c|cc|cc|}
\hline$N_{0}$ & Bahan & \multicolumn{2}{|c|}{ Jumlah \% } & \multicolumn{2}{l|}{ Individual } & \multicolumn{2}{c|}{ Comulative } \\
\hline 1 & Agragat Kasar & 17.5 & $\%$ & 210 & gram & 210 & gram \\
\hline 2 & Agragat Medium & 33 & $\%$ & 396 & gram & 606 & gram \\
\hline 3 & Agragat Halus & 40 & $\%$ & 480 & gram & 1086 & gram \\
\hline 4 & Filler & 2 & $\%$ & 24 & gram & 1110 & gram \\
\hline 5 & Limbah Granit & 7.5 & $\%$ & 90 & gram & 1200 & gram \\
\hline
\end{tabular}

Tabel 8 Penyesuaian proporsi campuran Laston / AC-(L) dengan variasi limbah batu granit $30 \%$

\begin{tabular}{|c|c|c|c|c|c|}
\hline $\mathrm{N}_{0}$ & Bahan & Jumlah & & Individual & Comulative \\
\hline 1 & Agragat Kasar & 16.4 & $\%$ & 196.8 gram & 196.8 gram \\
\hline 2 & Agragat Medium & 30.92 & $\%$ & 371 gram & 567.9 gram \\
\hline 3 & Agragat Halus & 37.48 & $\%$ & 449.8 gram & 1018 gram \\
\hline 4 & Filler & 1.87 & $\%$ & 22.44 gram & 1040 gram \\
\hline 5 & Aspal & 6.3 & $\%$ & 75.6 gram & 1116 gram \\
\hline 6 & Limbah Granit & 7.029 & $\%$ & 84.35 gram & 1200 gram \\
\hline
\end{tabular}

Sumber : (Data diolah)

\subsubsection{Pengujian Sample}

1. Bersihkan benda uji dari kotoran yang menempel.

2. Berilah nomor pada masing-masing benda uji.
3. Ukur tinggi benda uji tersebut gunakan mistar yang presisi.

4. Timbang benda uji dengan timbangan yang sensitive.

5. Rendam benda uji dalam air kira-kira 24 jam pada suhu ruang.

6. Timbang dalam air untuk mendapatkan berat isi, setelah itu timbang lagi benda uji tesebut dalam kondisi kering permukaan jenuh (benda uji diusap dengan handuk).

7. Rendamlah benda uji aspal panas atau benda uji tar dalam bak perendam (Waterbath) selama 30 sampai 40 menit atau dipanaskan didalam oven selama 2 jam dengan suhu tetap $60^{\circ} \mathrm{C}$ untuk benda uji aspal dingin masukkan benda uji tar. Untuk benda uji aspal dingin masukkan benda uji dalam oven selama minimum 2 jam dengan suhu tetap $25^{\circ} \mathrm{C}$.

\section{HASIL DAN PEMBAHASAN}

Hasil Acuan

Tabel 9 Rekapitulasi hasil perhitungan sampel acuan

\begin{tabular}{|c|c|c|c|c|c|c|}
\hline \multirow{4}{*}{$\begin{array}{l}\text { Kode } \\
\text { Briket }\end{array}$} & \multirow{4}{*}{ Koreksi } & \multicolumn{3}{|c|}{ Stabilitas } & \multirow{3}{*}{$\begin{array}{c}\begin{array}{c}\text { Pelelehan } \\
\text { (Flow) }\end{array} \\
\text { (F) }\end{array}$} & \multirow[b]{2}{*}{$\begin{array}{c}\text { Hasil Bagi } \\
\text { Marshal }\end{array}$} \\
\hline & & \multirow{2}{*}{$\begin{array}{c}\text { Bacaan } \\
\text { Pada Alat }\end{array}$} & \multirow{2}{*}{$\begin{array}{c}\begin{array}{c}\text { Kalibrasi } \\
\text { Proving } \\
\text { Ring }\end{array} \\
\begin{array}{c}\text { L x } \\
\text { Konversi }\end{array}\end{array}$} & \multirow{2}{*}{$\begin{array}{c}\begin{array}{c}\text { Setelah } \\
\text { Dikoreksi }\end{array} \\
\begin{array}{c}\text { M x } \\
\text { Koreksi } \\
\text { benda uji }\end{array}\end{array}$} & & \\
\hline & & & & & & $\mathrm{N} / 0$ \\
\hline & & L & M & $\mathbf{N}$ & 0 & $\mathbf{P}$ \\
\hline 1 & 12,42 & 90 & 1118 & 1118 & 3,6 & 310,56 \\
\hline 2 & 12,42 & 93 & 1155 & 1155 & 3,6 & 320,83 \\
\hline 3 & 12,42 & 97 & 1205 & 1205 & 3,2 & 376,56 \\
\hline \multicolumn{4}{|c|}{ Rata-rata } & 1159,33 & 3,47 & 334,42 \\
\hline
\end{tabular}

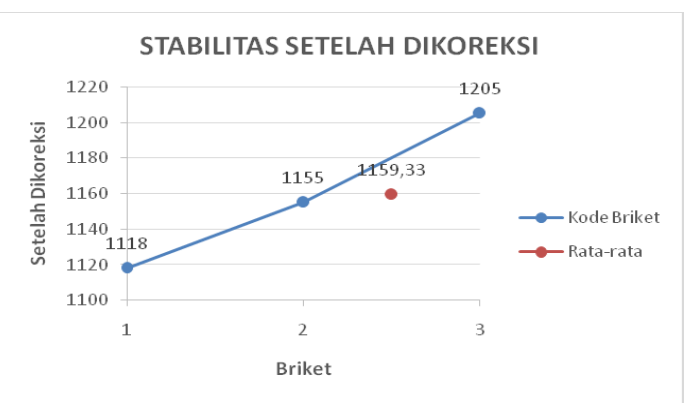



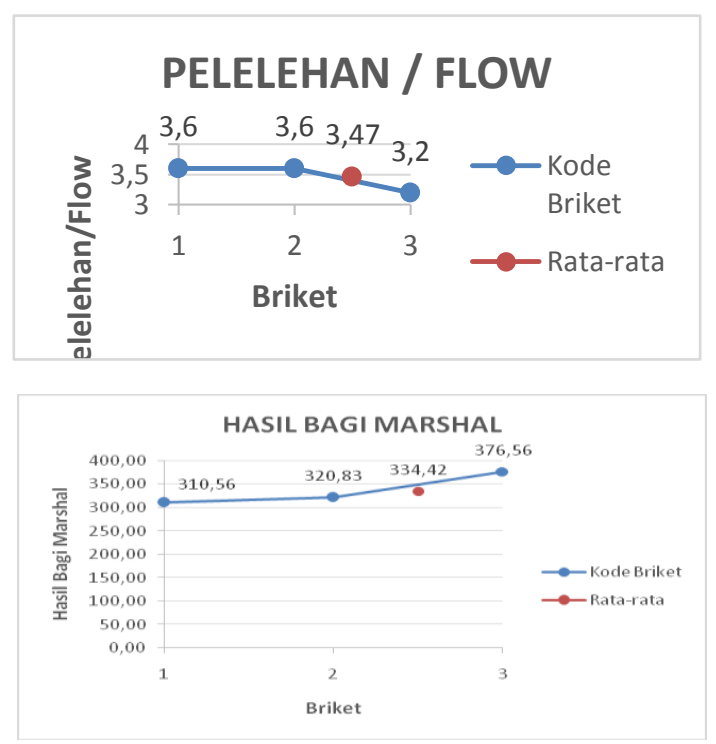

Tabel 10 Rekapitulasi Hasil Perhitungan dengan campuran Limbah Granit 10\%

\begin{tabular}{|c|c|c|c|c|c|c|}
\hline \multirow{4}{*}{$\begin{array}{l}\text { Kode } \\
\text { Briket }\end{array}$} & \multirow{4}{*}{ Konversi } & \multicolumn{3}{|c|}{ Stabilitas } & \multirow{3}{*}{$\begin{array}{c}\text { Pelelehan } \\
\text { (Flow) }\end{array}$} & \multirow[b]{2}{*}{$\begin{array}{r}\text { Hasil Bagi } \\
\text { Marshal }\end{array}$} \\
\hline & & \multirow{2}{*}{$\begin{array}{c}\text { Bacaan } \\
\text { Pada Alat }\end{array}$} & \multirow{2}{*}{$\begin{array}{c}\begin{array}{c}\text { Kalibrasi } \\
\text { Proving } \\
\text { Ring }\end{array} \\
\text { Lx } \\
\text { Konversi }\end{array}$} & \multirow{2}{*}{$\begin{array}{c}\begin{array}{c}\text { Setelah } \\
\text { Dikoreksi }\end{array} \\
\text { M x } \\
\text { Koreksi } \\
\text { benda uji }\end{array}$} & & \\
\hline & & & & & & N/O \\
\hline & & $\mathbf{L}$ & M & $\mathbf{N}$ & o & $\mathbf{P}$ \\
\hline 1 & 12,42 & 76 & 944 & 944 & 3,65 & 258,63 \\
\hline 2 & 12,42 & 73 & 907 & 907 & 3,25 & 279,08 \\
\hline 3 & 12,42 & 71,4 & 887 & 887 & 4,9 & 181,02 \\
\hline
\end{tabular}

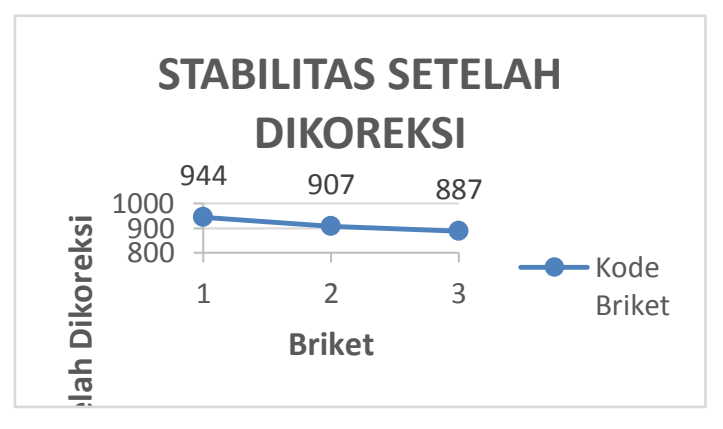

\section{PELELEHAN / FLOW}

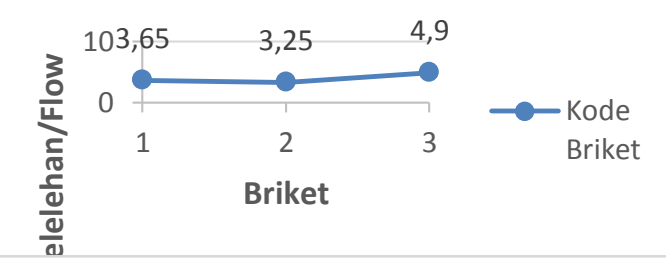

\section{HASIL BAGI MARSHAL}

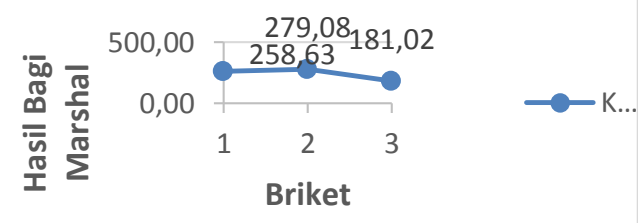

Tabel 11 Rekapitulasi Hasil Perhitungan dengan campuran Limbah Granit 20\%

\begin{tabular}{|c|c|c|c|c|c|c|}
\hline \multirow{4}{*}{$\begin{array}{l}\text { Kode } \\
\text { Briket }\end{array}$} & \multirow{4}{*}{ Konversi } & \multicolumn{3}{|c|}{ Stabilitas } & \multirow{3}{*}{$\begin{array}{c}\text { Pelelehan } \\
\text { (Flow) }\end{array}$} & \multirow[b]{2}{*}{$\begin{array}{c}\text { Hasil Bagi } \\
\text { Marshal }\end{array}$} \\
\hline & & \multirow{2}{*}{$\begin{array}{c}\text { Bacaan } \\
\text { Pada Alat }\end{array}$} & \multirow{2}{*}{\begin{tabular}{|c|}
$\begin{array}{c}\text { Kalibrasi } \\
\text { Proving } \\
\text { Ring }\end{array}$ \\
$\begin{array}{c}\text { Lx } \\
\text { Konversi }\end{array}$ \\
\end{tabular}} & \multirow{2}{*}{$\begin{array}{c}\begin{array}{c}\text { Setelah } \\
\text { Dikoreksi }\end{array} \\
\text { M x } \\
\text { Koreksi } \\
\text { benda uji }\end{array}$} & & \\
\hline & & & & & & $\mathrm{N} / 0$ \\
\hline & & L & M & $\mathrm{N}$ & 0 & $\mathbf{P}$ \\
\hline 1 & 12,42 & 86 & 1068 & 1068 & 4,5 & 237,33 \\
\hline 2 & 12,42 & 84 & 1043 & 1043 & 3,8 & 274,47 \\
\hline 3 & 12,42 & 83,8 & 1041 & 1041 & 3,7 & 281,35 \\
\hline
\end{tabular}

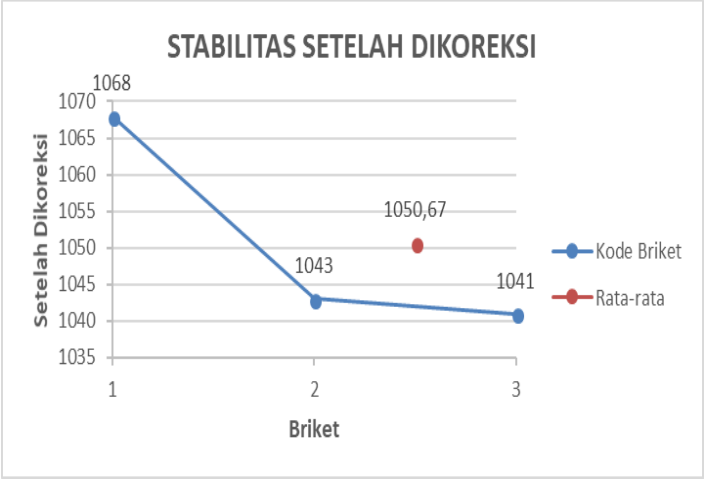

\section{PELELEHAN / FLOW}

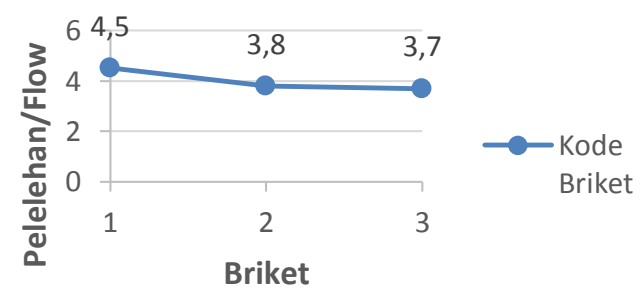




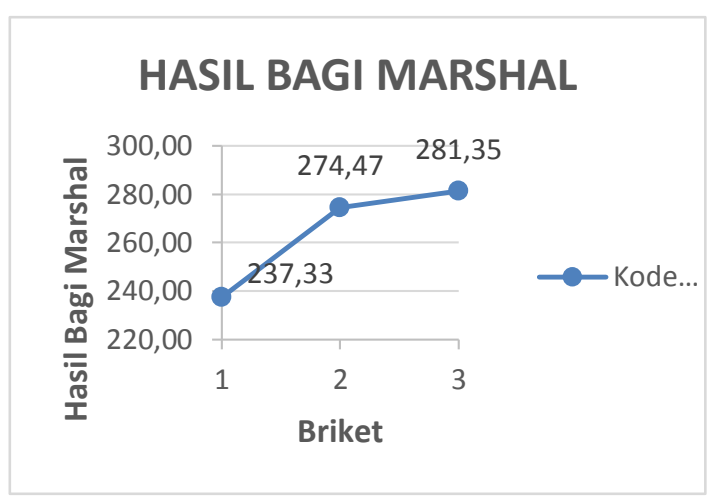

Tabel 12 Rekapitulasi Hasil Perhitungan dengan campuran Limbah Granit 30\%

\begin{tabular}{|c|c|c|c|c|c|c|}
\hline \multirow{4}{*}{$\begin{array}{l}\text { Kode } \\
\text { Briket }\end{array}$} & \multirow{4}{*}{ Konversi } & \multicolumn{3}{|c|}{ Stabilitas } & \multirow{3}{*}{$\begin{array}{c}\text { Pelelehan } \\
\text { (Flow) }\end{array}$} & \multirow[b]{2}{*}{$\begin{array}{l}\text { Hasil Bagi } \\
\text { Marshal }\end{array}$} \\
\hline & & \multirow{2}{*}{$\begin{array}{l}\text { Bacaan } \\
\text { Pada Alat }\end{array}$} & \multirow{2}{*}{\begin{tabular}{|c}
$\begin{array}{c}\text { Kalibrasi } \\
\text { Proving } \\
\text { Ring }\end{array}$ \\
$\begin{array}{c}\text { Lx } \\
\text { Konversi }\end{array}$ \\
\end{tabular}} & \multirow{2}{*}{\begin{tabular}{|c|}
$\begin{array}{c}\text { Setelah } \\
\text { Dikoreksi }\end{array}$ \\
$\begin{array}{c}\text { M x } \\
\text { Koreksi } \\
\text { benda uji }\end{array}$ \\
\end{tabular}} & & \\
\hline & & & & & & $\mathrm{N} / \mathrm{O}$ \\
\hline & & L & M & $\mathrm{N}$ & 0 & $P$ \\
\hline 1 & 12,42 & 87 & 1018 & 977 & 4,1 & 238,36 \\
\hline 2 & 12,42 & 83 & 1031 & 989,76 & 4,2 & 235,66 \\
\hline 3 & 12,42 & 84 & 1043 & 1001,28 & 4,8 & 208,60 \\
\hline
\end{tabular}

\section{STABILITAS SETELAH} DIKOREKSI
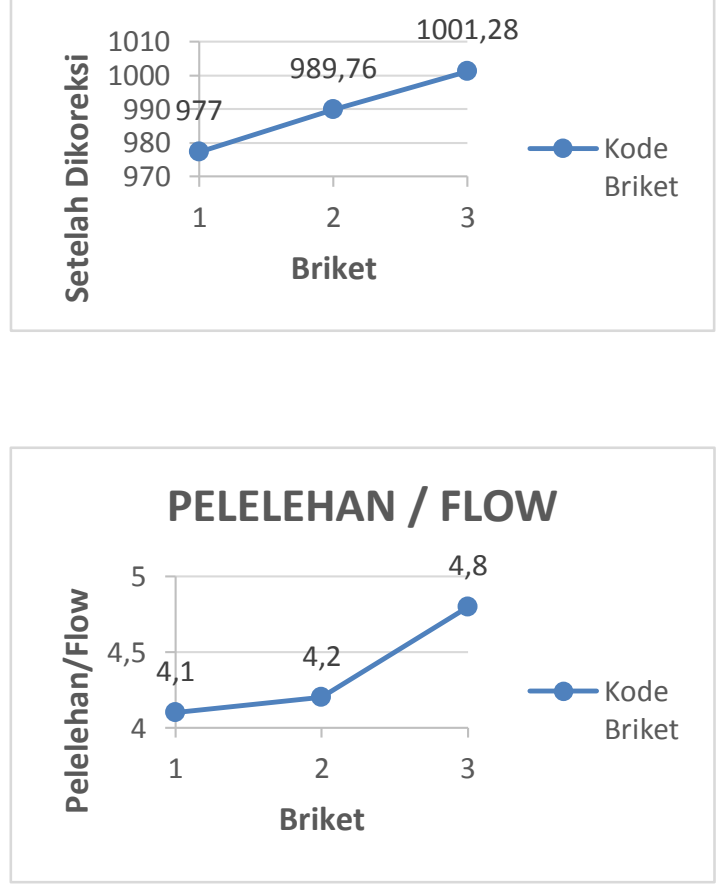

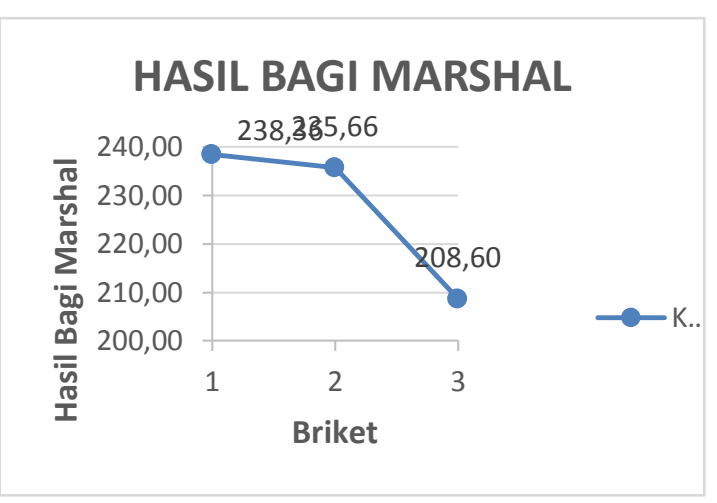

Dari Beberapa Percobaan AC (L) dengan campuran limbah batu granit dalam porsi $10 \%, 20 \%, 30 \%$ kita bisa melihat pada grafik dibawah ini:

Tabel 13 kadar optimum limbah batu granit

\begin{tabular}{|c|c|c|c|}
\hline PERSENTASE & $\begin{array}{c}\text { STABLLTASSETELAH } \\
\text { DIKOREKSI }\end{array}$ & $\begin{array}{c}\text { PELELEHAN/ } \\
\text { FLOW }\end{array}$ & $\begin{array}{c}\text { HASLL BAGI } \\
\text { MARSHAL }\end{array}$ \\
\hline $10 \%$ & 912,67 & 3,93 & 232,03 \\
\hline $20 \%$ & 1050,67 & 4 & 262,67 \\
\hline $30 \%$ & 9999,44 & 4,37 & 226,59 \\
\hline
\end{tabular}

Sumber : (Data diolah) 


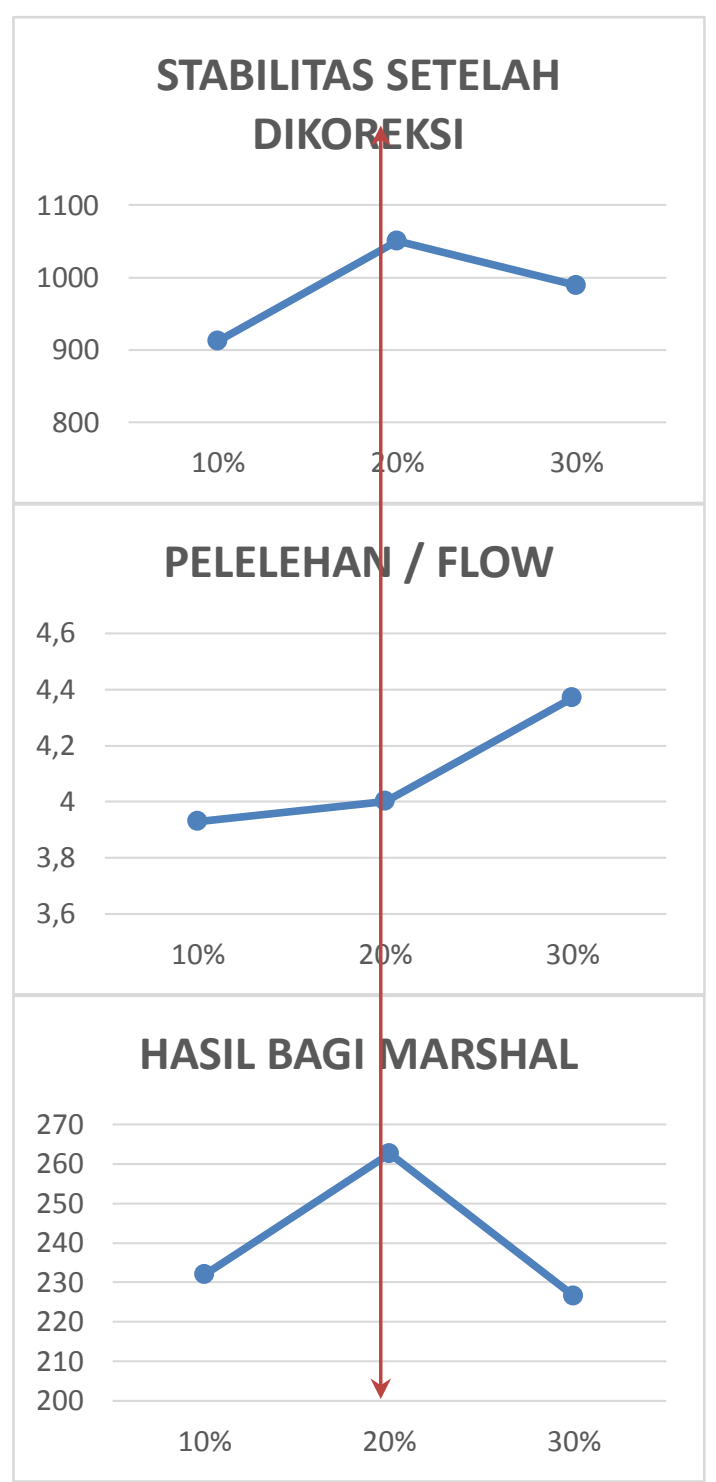

\section{Kadar optimum}

Jadi, dari grafik diatas didapatkan nilai terbesar pada kadar batu granit di presentase $20 \%$.

\section{KESIMPULAN}

1. Dari hasil pengujian Marshall, campuran Laston dengan limbah batu granit sebagai pengganti agregat kasar, dengan kadar limbah batu granit mulai $10 \%, 20 \%, 30 \%$, diketahui ada pengaruh kualitas campuran terhadap karakteristik marshall.

2. Campuran aspal Laston dengan limbah batu granit sebagai pengganti agregat kasar, pada kadar limbah batu granit optimum 20\%, menghasilkan kualitas campuran : marshallstability 1050.67 $\mathrm{kg}$, pelelehan / flow $4.00 \mathrm{~mm}$, marshall SARAN

quotient $262.67 \mathrm{~kg} / \mathrm{mm}$,

Pemanfaatan limbah batu granit dapat juga digunakan untuk campuran aspal seperti Latasir, Lataston, ATB dan campuran lainnya.

\section{DAFTAR PUSTAKA}

Anonim.1997. Manual Kapasitas Jalan Indonesia (MKJI), Bina Marga

Anonym."Manfaat Batu Granit Dan Proses Terbentuknya".

(Online)

http://www.agrobisnisinfo.com/2016/03 Imanfaat-batu-granit-dan-proses.html. Diakses 13Maret2018.

Cristady Hardiyatmo, Hary. 2009. Pemeliharaan Jalan Raya. Yogyakarta : Gadjah Mada University Press.

Direktorat Jenderal Bina Marga. 2010. Spesifikasi Umum Bina Marga 2010

Devisi 6. Jakarta : Kementrian Pekerjaan Umum Direktorat Jenderal Bina Marga.

Direktorat Jenderal Bina Marga. 2010. Spesifikasi Umum Binamarga 2010

Revisi 2. Jakarta : Kementrian Pekerjaan Umum Direktorat Jenderal Bina Marga.

Farah Farah. Pengertian Batu Granit Dan Gambarnya.

(Online). https://ilmugeografi.com/geologi/penge rtian-batu-granit . Diakses 13Maret2018

Hendarsin, Shirley L. 2000. Perencanaan Teknik Jalan Raya. Bandung : Politeknik

Negeri Bandung.

Sukirman, S. 1999. Perkerasan Lentur Jalan Raya.Bandung : Nova

Sukirman, S. 2003. Beton Aspal Campuran Panas. Bandung : Granit

Tatonas, Marshal Tes Set Tas - 320 